This item was submitted to Loughborough's Research Repository by the author.

Items in Figshare are protected by copyright, with all rights reserved, unless otherwise indicated.

\title{
Overcoming suicidal persons' resistance using productive communicative challenges during police crisis negotiations
}

\section{PLEASE CITE THE PUBLISHED VERSION}

https://doi.org/10.1093/applin/amy065

\section{PUBLISHER}

Oxford University Press (c) The Author(s)

VERSION

AM (Accepted Manuscript)

\section{PUBLISHER STATEMENT}

This is a pre-copyedited, author-produced version of an article accepted for publication in Applied Linguistics following peer review. The version of record SIKVELAND, R.O., KEVOE-FELDMAN, H. and STOKOE, E., 2020. Overcoming suicidal persons' resistance using productive communicative challenges during police crisis negotiations. Applied Linguistics, 41 (4), pp.533-551 is available online at: https://academic.oup.com/applij/article/41/4/533/5305680 and https://doi.org/10.1093/applin/amy065.

\section{LICENCE}

CC BY-NC-ND 4.0

\section{REPOSITORY RECORD}

Sikveland, Rein, Heidi Kevoe-Feldman, and Elizabeth Stokoe. 2019. "Overcoming Suicidal Persons' Resistance Using Productive Communicative Challenges During Police Crisis Negotiations”. Loughborough University. https://hdl.handle.net/2134/36411. 


\section{Overcoming suicidal persons' resistance using productive communicative challenges during police crisis negotiations}

This paper reveals how negotiators, from the police and emergency call centres, overcome resistance towards the negotiation from suicidal persons in crisis. Communication guidance to hostage and crisis negotiators recommends against challenging the person in crisis, focusing instead on a softer, rapportful approach. Using conversation analysis, we investigate how negotiators deal with resistance, turn by turn, in encounters collected from British police negotiators' field recordings, and American police 9-1-1 dispatch telephone calls. In contrast to existing communication guidance, we show that and how challenges can be productive for bringing about positive shifts in suicidal persons' behaviour. We demonstrate how negotiators challenge the reasoning in their interlocutors' resistant responses and leverage these challenges productively in the next turn. By studying real (rather than hypothetical or simulated) negotiations, the study reveals the tacit expertise of negotiators and the communicative practices that optimize negotiation outcomes. These research findings have significant implications for existing communication guidance showing how negotiations are managed locally through the linguistic design of turns of talk.

Keywords: Suicide, negotiation, crisis, conversation analysis, communication training.

\section{INTRODUCTION}

This paper examines how police negotiators and police call-centre dispatchers do interactional work to overcome resistance from suicidal persons in crisis. One of the basic problems for these professionals is that their interlocutor - a person thinking about or threatening suicide - has, from their perspective, good reasons for initiating such a course of action, and frequently resist the negotiator's attempts to persuade them otherwise (Miles 2013). During a negotiation, crisis negotiators have to overcome challenges of various kind. One key challenge, and a priority for negotiators is to encourage persons in crisis to locate themselves physically in a safer position than they might currently be at (e.g., on a bridge, on a chair with a noose around their neck). In Extract 1, the person in crisis (PiC) is standing on a roof. The negotiator's (N1) first order of business is to get them to a safe place.

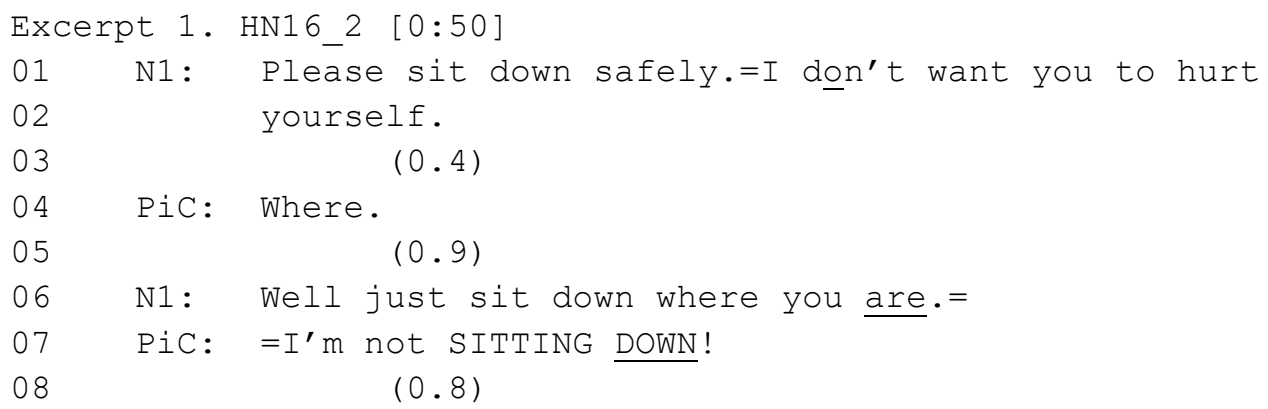




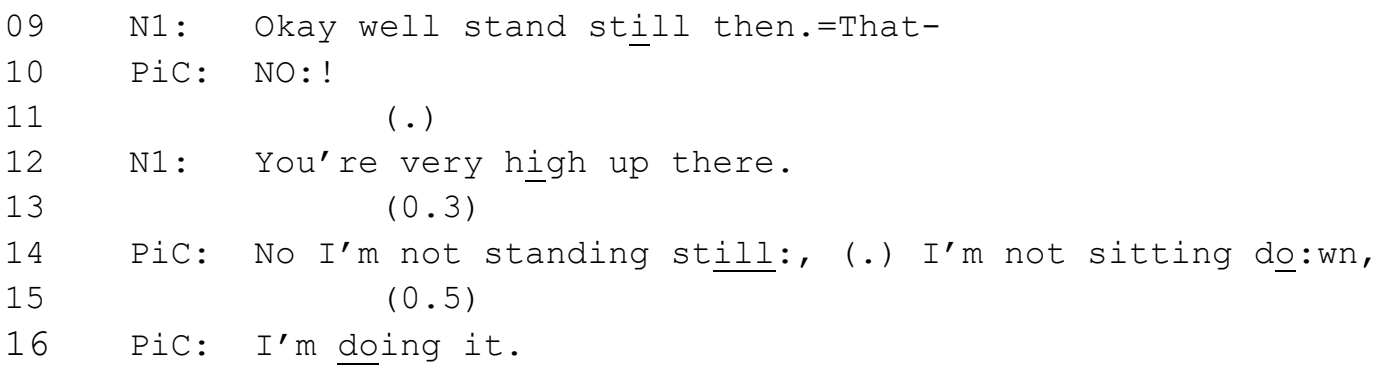

N1 formulates a request, 'Please sit down safely.' (line 01), and gives the account that he does not want the PiC to 'hurt yourself.' (lines 01-02). It seems initially that, after the silence at line 03 , the PiC is willing to find a seat, as he asks, 'Where.' (line 04). But after N1 suggests to sit 'where you are.' (line 06), the PiC yells his resistance, and rejects the request (lines 07, 10 and 14). The extract ends with an explicit threat that $\mathrm{PiC}$ is 'doing it.' (line 16; the PiC elaborates on this threat in his subsequent talk).

Extract 1 is similar to other cases in which negotiators must continue to talk with people who resist offers, requests, instructions, and other actions initiated by the negotiator. The analysis we present in this paper shows how negotiators identify resources they can use as leverage for getting a person in crisis to come down; to accept help; to choose life. As noted already, a core goal is to get the PiC out of immediate danger, and to enable a conversation in which the $\mathrm{PiC}$ is unlikely to fall or jump. Consider the following two examples of seemingly successful scenarios, in which negotiators formulate a request or directive to the person in crisis who, in the next turn, immediately complies by reporting a change in their stance with regard to their decision to take their life:

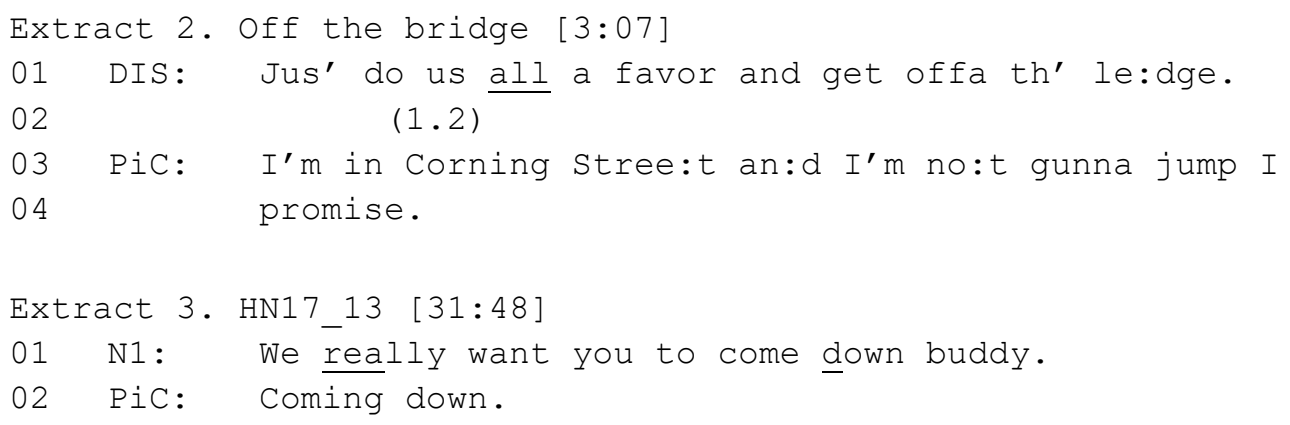

In both cases, the PiC states their intent to stay alive - not to jump; to come down. Of course, neither of these fragments appears at the start of the encounters. They are turning points, coming after the $\mathrm{PiC}$ has displayed strong and continued resistance to the police dispatcher's (Extract 2) and police negotiator's (Extract 3) efforts. Our interest is in what kinds of communicative practices lay the groundwork for these turning points in the negotiations. One feature of both extracts is that neither of the turns taken by the PiCs is direct agreements with the negotiators' previous turns. In Extract 2, the PiC supplies information about their location, and a promise not to jump - not an agreeing 'okay, I will.' In Extract 3, the PiC states their intent to come down - he does not agree to come down. In our analysis of crisis negotiations, one key observation is that persons in crisis display independence and agency in the actions they do. It turns out that negotiators can use these agentive statements of intent productively, to leverage a successful outcome. 
This paper aims to identify communicative actions taken by negotiators that are productive for getting the $\mathrm{PiC}$ to shift position, from a commitment to suicide to a commitment to staying alive. We start by summarizing and reflecting upon previous work dedicated to understanding effective communication in crisis negotiation, including a brief overview of theoretical and methodological approaches to studying positive behaviour shifts (turning points) in negotiations.

\section{CRISIS NEGOTIATION AND SUICIDE}

Over the past fifty years, hostage and crisis communication has been researched extensively. Crisis negotiation has emerged as a large and interdisciplinary field, with a strongly applied focus from theory and experimentation to modelling and training. Psychologists, behavioural scientists, linguists and law enforcement professionals work together to understand and optimize crisis negotiation practice. Rubin (2016) outlines the history and evolution of crisis negotiation as research and practice, noting the broadening definition from hostage negotiation to crisis negotiation. Research questions are wide-ranging, from establishing the features of different types of hostage situations to the behavioural patterns and psychological attributes of negotiators (see Knowles 2016 for an overview). At the same time, our understanding of suicide - from cause to prevention - has evolved in psychological and medical domains, often in overlap with the crisis negotiation literature. As Charlés (2007) notes, 'hostage incidents are not the primary type of critical incident with which crisis negotiators deal ... Rather, negotiators often face people in the midst of an escalated personal crisis' (p. 52). Suicide ranks as the most common cause of death for young people, and approximately 6,000 persons died from suicide in 2016 only in the UK ('Office for National Statistics' 2017). For every completed suicide there are an estimated 100 attempts requiring attention from first responders including emergencies; and for crisis response teams about half the cases are with people who threaten suicide (McMains \& Mullins 2014).

To understand the dynamics of a suicide negotiation, many researchers start by attempting to establish the likelihood that a person having suicidal thoughts will act upon them, including factors such as their motives, mental health status, psychiatric history, drug or alcohol history, and criminal history (e.g., Husky et al. 2017; Klonsky \& May 2014; for a sociological analysis, see Atkinson 1983). While such factors are important for assessing risk and intent, we argue that once a threat is realized to the point that a negotiation is underway, a priori factors and variables are less useful to negotiators than understanding how to facilitate a productive conversation, avoiding escalation and disengagement from the person in crisis. Despite masses of research on suicide risk, prevention and treatment, on the one hand, and crisis negotiation on the other, the suicide negotiation field is limited for a number of reasons. One reason is, quite simply, and sadly, that understanding the experience, risk and cause of suicidal ideation is constrained to (relatively) small participant cohorts of 'incomplete' suicides. Another reason is that researchers focus on the antecedents to aftermath of suicide, rather than what actually happens during the course of committing suicide, or not, in the data provided by recorded negotiations with suicidal persons in crisis. Kleiman and Knock (2018) stress the importance of understanding 'real time assessment of 
suicidal thoughts and behaviours' (e.g., using smartphone and other technologies) over extended periods, to increase practitioners' ability to observe and intervene suicidal ideation as it 'unfolds in real-time' (p. 33). However, we argue that it is important to examine another kind of real time unfolding: the recorded negotiations that start with a commitment to committing suicide, and end, most often in our data, with a commitment to staying alive. In this paper we are particularly interested in the work negotiators do (and get trained to do) in bringing about turning points, or positive behaviour shifts as we will define them, in the person in crisis' stance towards the negotiation. We reflect on existing work in the next section.

\section{COMMUNICATION STRATEGIES FOR NEGOTIATING TOWARDS BEHAVIOUR CHANGE}

There is a great deal of research dedicated to understanding and improving hostage and crisis negotiation practice. Much of this work is located in, or strongly influenced by, the psychology of social cognition and behavioural change. One of the most cited models for negotiation practice is the 'Behavioural Change Stairway Model'. This model developed by the FBI's Crisis Negotiation Unit, and outlines the relationship-building process involving the negotiator and subject, aiming to achieve a peaceful settlement of the critical incident (Vecchi et al. 2005).

BCSM consists of five stages: active listening, empathy, rapport, influence, and behavioural change. The importance of the three first stages is intuitively sensible and compelling, and it seems natural that positive influence and behavioural change are more likely if the negotiator is able to first build a positive and trustworthy relationship. The first three stages overlap with almost any articulation of what counts as 'communication skills' across professional settings (e.g., mediation, counselling, police interviewing, medical encounters) and the model is referred to in numerous other popular science communication and negotiation books (e.g., Voss \& Raz 2016). 'Active listening', for example, is described in terms of uses of 'mirroring', 'summarizing', 'paraphrasing', 'emotional labelling', 'effective pauses', 'minimal encouragers', and 'open-ended questions' (e.g., Royce 2005; Vecchi et al. 2005). However, readers familiar with conversation analysis will know that what such 'skills' look like in real talk - how they are designed and what they accomplish is more complex. For instance, 'summarizing' someone else's talk can be a powerful way demonstrate shared understandings, to drive an institutional encounter forward, but also to transform versions of events in ways that undermine one party or another (Houwen \& Sliedrecht 2016). And the recommendation to use 'open-ended' rather than 'closed' questions conflicts with research that shows how ostensibly 'closed' yes-no interrogatives routinely generate more than 'yes' or 'no' as answers. For example, Stokoe and Sikveland (2017) showed how police officers' questions posed in a linguistically closed format (e.g., 'can you X') elicit full accounts from suspects in police interviews. Miles (2013) also found that closed and open-ended questions can be productive for negotiation encounters (see also Roulston 2010); overall, what generates a response has less to do with the grammatical form alone and more to do with the action carried by the grammar (e.g., Fox et al. 2013). 
How these negotiation skills bring about influence and behavioural changes is mostly glossed rather than specified in terms of the nuts and bolts of producing words and turns at talk. As Rubin (2016) notes, recommendations in the BCSM, such as 'rapport building' and 'influence', are 'amorphous and nebulous': 'it is less clear what the linguistic features are that trainers can point to in order to help negotiators achieve' (p. 9). A handful of studies examine live, real cases of crisis negotiation (e.g., Charlés 2007; Garcia 2017; Rubin 2016), but these remain the minority of the overall literature on communication in this field. Consequently, there is little empirical, bottom-up scrutiny of real crisis encounters, and of how specific actions (questions, proposals, requests, etc., and their linguistic forms) build influence and behavioural change - what we will describe as observable 'shifts' in crisis negotiations.

The proposed relevance of questions for bringing about positive or negative shifts in behaviour in the crisis negotiation literature goes beyond open and closed formats. For example, while the basic function of a question is to gain some information from an interlocutor, thereby driving the interaction forwards, a question can also challenge or refute a counterpart's argument or position (Miles, 2013). Researchers on crisis negotiation have thereby urged caution regarding the use of certain types of questions. For instance, James (2007: 52) recommends that crisis negotiators should not ask 'Why?' questions. He writes that "It is my contention that "why" questions are generally poor choices for obtaining more information. Even though they may provide the client with an opening to talk more, they also make the client defend his or her actions.' We find similar arguments elsewhere. For example, based on Goffman's 'face' theory, Tracy (2002) argues that investigative questions such as 'did you see the shooting or only hear it?' evoke a threat to face when posed to emergency callers. In turn, callers may display belligerence in their response.

On the other hand, crisis negotiators who adopt, or 'mirror', the negotiatee's own terms have been found to be more successful in getting to a positive negotiation outcome. For example, Taylor and Thomas (2008), operationalizing 'mirroring' as 'linguistic style matching', or word-to-word correspondence between negotiator and negotiatee consecutive turns, found that negotiations were more likely to have a successful outcome when linguistic matching was stable as opposed to the greater instability found in unsuccessful cases. This matching involved a 'reciprocation of positive affect, a focus on the present rather than the past, and a focus on alternatives rather than on competition.' (p. 263). Such findings add some weight to the generally accepted position that crisis negotiators should not criticize or judge the person in crisis (Charlés 2007), or otherwise challenge them. In contrast, Rogan (2011) suggests that, as problem solving is central to crisis management, it may be appropriate to challenge a suicidal person to "effectuate the subject's surrender" (p. 36). However, these studies do not provide empirical evidence of the linguistic and sequential specifics of the risky, and perhaps less risky, questions, requests or other actions relevant to behavioural change, and turning points. As our analysis will reveal, posing challenges (in question or other formats) sometimes leads to positive rather than negative shift in a person in crisis's stance towards the negotiation.

More than 50 years ago, one of the founders of conversation analysis, Harvey Sacks, wrote his PhD thesis on telephone calls to the Los Angeles Suicide Prevention Center, whilst he was a member of research staff at an emergency psychiatric clinic (Sacks 1966). Sacks's thesis remains one of the few studies to provide insight into the real-time unfolding of 
communication between suicidal persons in crisis and a professional whose job is to help. In 1978, Max Atkinson wrote that Sacks's work on suicide had received little attention from anyone other than ethnomethodologists, and it is unreferenced in the crisis communication literature. This paper reinvigorates Sacks's work on suicide, using the methods he developed to analyse conversation. We will show how people with 'no one to turn to' are helped by police professionals in ways that are productive for their eventual decision to stay alive.

\section{DATA AND METHOD}

Two datasets provide the empirical materials for our research. First, a UK police Hostage and Crisis Negotiation Unit supplied audio recordings of interactions between people in crisis (PiCs) and negotiators (Ns), recorded at the scene as a routine part of their job. The data were provided as part of a larger, 3-year, study of crisis negotiation conducted from 2016-2018. The study is based on 14 individual cases ( 31 hours in total), for which the current paper represents one of the practices found relevant to manage resistance from persons in crisis. In 13 cases, the $\mathrm{PiC}$ survived (including one where the $\mathrm{PiC}$ was shot by the police), and one case had a negative outcome (that is, the PiC died from an accident at the end of the recording). Negotiations are usually led by one negotiator ('N1'), who is supported by a team of three other negotiators. Interactions between PiCs and N1s were sometimes on the telephone and sometimes face-to-face (often at a distance; e.g., PiC is on a roof while N1 and N2 are on the ground).

The second data set comes from a USA 9-1-1 Emergency call centre. Citizens phone to request emergency services for incidents ranging from car accidents to domestic disputes and suicide. The data were collected as part of a larger project of how 9-1-1 callers manage to give hysterical callers medical instruction in a time of crisis. From the larger collection, 35 calls were identified as suicide calls, of which 25 involved people calling because they feared a loved one was threatening suicide. Eight were from people who themselves report suicidal ideation or intent. Out of the eight calls, the present analysis is based on one in which a caller, recently escaped from a hospital for mental health treatment, is now on the side of the bridge threatening to jump. The total data reported in this paper represent encounters ranging from 17 minutes in the 9-1-1 dataset, to 4.5 hours in the crisis negotiation dataset. Crucially, for the purposes of this paper, both police negotiators and emergency dispatchers are in a similar position, talking to a person in crisis who is already on a suicidal course of action. These two types of settings have not previously been compared, and we offer for the first time research exploring what communicative practices are effective, and ineffective, in both these settings.

Ahead of the study, ethical approval was secured on behalf of the Hostage and Crisis Negotiation Unit who supplied that data, and from ANON University Ethics Committee. Because the project was led by hostage and crisis police services, data were supplied by the police themselves, according to their own internal data management process. Like police interviews of suspects and witnesses, recordings were already made by police in situ, as part of routine work practice. They were provided to us after the possibility of formal consent (pre or post-hoc) could be granted, and on the basis that they were used anonymously (see below) and stored according to the usual standards for university research data management (i.e., 
under encryption). The second data set received IRB human subject approval from ANON University's Ethics Committee, which includes an approval letter to use the data for training and research from the participating State Police. Lakeman \& Fitzgerald (2009) notes that 'ethical problems and difficulties in obtaining approval to involve people who are suicidal in research has contributed to the current paucity of research that explores the suicidal experience' (p. 10); ours is the first study to use conversation analysis to explore live crisis negotiation with suicidal people in crisis.

Conversation analysis (CA) builds on participants' demonstrable understandings within the interaction itself, rather than from analysts' a priori definitions and assumptions of what to look for, or what 'should' happen. In CA, definitions of a relevant phenomenon to study emerge as a result of the early stages of the analysis. Starting with a technical transcript of the recorded data, CA proceeds by repeatedly viewing or listening to the data and transcript, and demonstrates, by analysing the organization of conversation turn by turn, how the design of an activity (e.g., requests, complaints, instruction) places constraints on the ways that responses can be made (see, e.g., Atkinson \& Heritage 1984). In our analysis, we identified sequences in the data in which we had observed a shift - positive or negative - in the stance taken by person in crisis towards the negotiation and towards staying alive rather than completing suicide. We used CA to track and compare sequence and design features relevant to these shifts, focussing on how the shifts related to the negotiator's previous and concurrent actions. We came to define a negative shift as an intensified or maintained stance in the PiC's response; in contrast, we describe a positive shift as a demonstrably weaker stance taken by the PiC to resist the negotiator. To represent the trajectory of what are inevitably long and complex cases, the current paper reports from a relatively small sample of complete encounters. We aim to illustrate, for the first time, how negotiators use and challenge the negotiatee's reasoning productively, by highlighting a flaw in the terms that the PiCs themselves lay out in their resistance.

In the Analysis section we build our analytic claims case by case, presenting specific linguistic resources and demonstrate their relevance for negotiators to productively challenge the person in crisis. This is followed by cases which demonstrate negotiators' missed opportunities to do so.

\section{ANALYSIS}

The analysis demonstrates how, in subsequent turns of talk, a negotiator $(\mathrm{N})$ or emergency call dispatcher (DIS) may productively get a person in crisis (PiC), at least momentarily, to choose safety over harm, by 1) challenging a reasoned consequence based on the PiC's terms of resistance, and 2) leveraging this challenge in a way that the $\mathrm{PiC}$ does not, even cannot, refute. We will argue that these challenges are productive for two reasons: first, because refuting them would be unreasonable or irrational - the very characteristic PiCs are trying to avoid, and second, because the challenge is based on the PiC's own reasoning in their previous turn(s). The analysis is arranged as follows: In Extracts 4-6, the negotiator identifies and leverages upon a reasoned consequence of the PiC's argument, with positive outcomes for the interaction. We compare the strategies used in this core set of cases with Extracts 7 
and 8 , in which the $\mathrm{N}$ fails to challenge the PiC's resistance, and instead asks the $\mathrm{PiC}$ to agree to something which they may easily refute. What makes these failed attempts refutable is the reverse reason the core positive cases are irrefutable: the former are not leveraged upon logical reasoning. The negotiation is led by three different crisis negotiators in Extracts 4, 5, 7 and 8, and by a 911 dispatcher in Extract 6.

\section{CHALLENGING AN ACCOUNT BASED ON A REASONED CONSEQUENCE}

In Extract 4, the $\mathrm{N}$ initiates a proposal whereby he offers the $\mathrm{PiC}$ a cigarette in exchange for taking the noose off his neck (lines 01-02). Taking the noose off would eliminate the immediate threat, and possibly move the $\mathrm{PiC}$ into a safer territory for subsequent negotiation. We focus on how the $\mathrm{N}$ identifies and leverages upon a logical consequence of the PiC's resistant response.

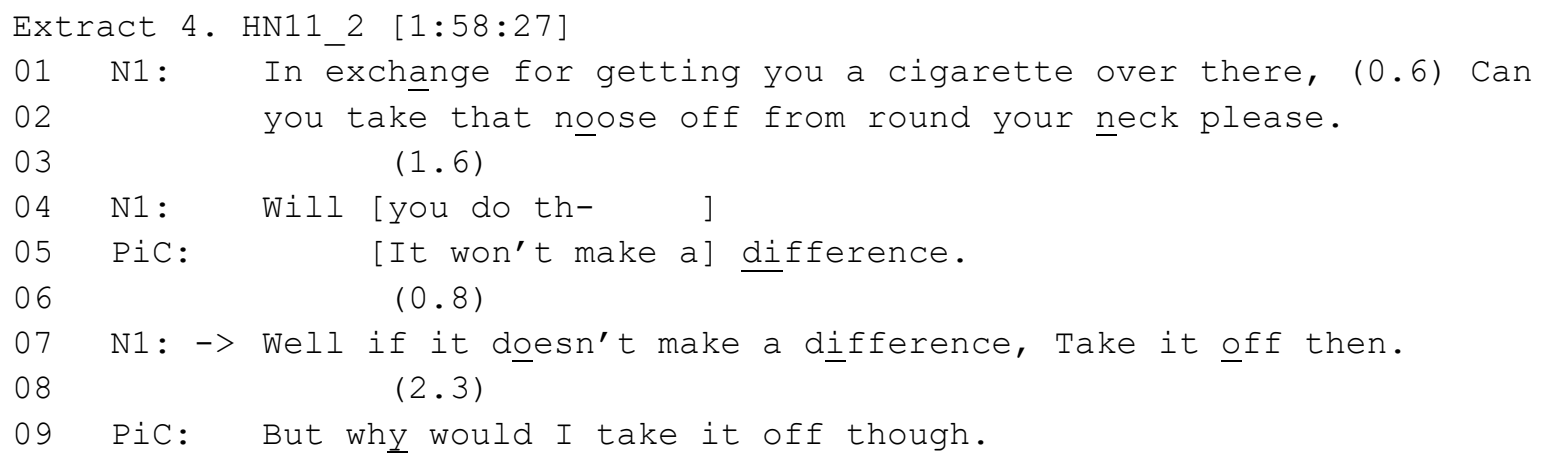

The negotiator's proposal (lines 01-02) is initially met with a long 1.6 seconds of silence (line 03), which forecasts the PiC's possible trouble with agreeing to his terms. The negotiator then pursues the proposal (line 04), but before he completes his turn, the PiC starts in overlap by rejecting the N's terms, 'It won't make a difference.' (line 05 ).

In this instance, while PiC's use of 'it' indexes the act of taking off the noose, this pronoun also implies that removing the noose would not change his intentions. After the silence at line $06, \mathrm{~N}$ works to undermine $\mathrm{PiC}$ 's rejection by expanding the sequence and using his turn as a resource for building our target challenge in the next turn, 'Well if it doesn't make a difference, Take it off then.' (line 07). This is an if-then construction (and an imperative), in which the turn-final 'then' marks the 'take it off' as a (logical) consequence of the preceding if-condition (Haselow 2011). N challenges PiC using PiC's own words, which is further supported by the well-preface: as Heritage (2015) noted, well-prefacing can set up a my-side basis of the responsive talk, whereby one possible use of the well-preface is to 'open the way for imitations of competition or one-upmanship' (p. 100). Here the negotiator uses the well-preface, and if-then construction, and one-ups $\mathrm{PiC}$ by using his own words, as it were, against him. The upshot is that using a well-preface and an if-then construction tied to the implications and consequence of 'it' (i.e., 'taking the noose off') not making a difference, the negotiator can disambiguate the indexical reference used by the $\mathrm{PiC}$ thereby undermining the logic of his account. 
The $\mathrm{PiC}$ remains silent for 2.3 seconds (line 08). A responsive action from the $\mathrm{PiC}$ is relevantly due, and in this sense, the silence belongs to $\mathrm{PiC}$. While a continued silence gap can form a break in progressivity (Schegloff 2007), it can also preserve the relevance of a response. The silence unfolds only as far as the participants allow, which, from N's point of view, can be a continued rather than failed opportunity to get a response. The unfolding silence proves productive in this case: when PiC does speak, rather than rejecting the negotiator's proposal, he solicits an account, 'But why would I take it off though.' (line 09). This account-solicitation opens an opportunity for $\mathrm{N}$ to make a next move beyond dealing with the rejection of taking off the noose. Proceeding from this sequence, N (not shown) responds by repeating his counter-challenge 'Well you've just said to me it doesn't make a difference (1.8) in which case take it off.', and continues by reiterating his initial proposal for how the $\mathrm{PiC}$ would be able to get a cigarette. Soon after, the positive shift happens as $\mathrm{PiC}$ takes the noose off, and the negotiation continues.

Extract 5 shows another negotiator identifying and leveraging upon a PiC's flawed logic, this time challenging the PiC's denial that he deliberately ignores the negotiator. In this case, before the extract, the $\mathrm{N}$ has worked to regain contact with the $\mathrm{PiC}$ and begins with a summons, which, after three rounds is met with silence each time. In line 1, the $\mathrm{N}$ shifts her strategy to gain the $\mathrm{PiC}$ attention with 'Don't ignore me,' which is a direct complaint about his lack of uptake. After the silence at line 02, the PiC responds with a counter that rejects her complaint (thereby rejecting her characterization of his action) when he says, 'I'm not ignoring ya.' (line 03). Our interest is in how the $\mathrm{N}$ works to leverage this response towards opening up a dialog with a $\mathrm{PiC}$ who remained silent for some time.

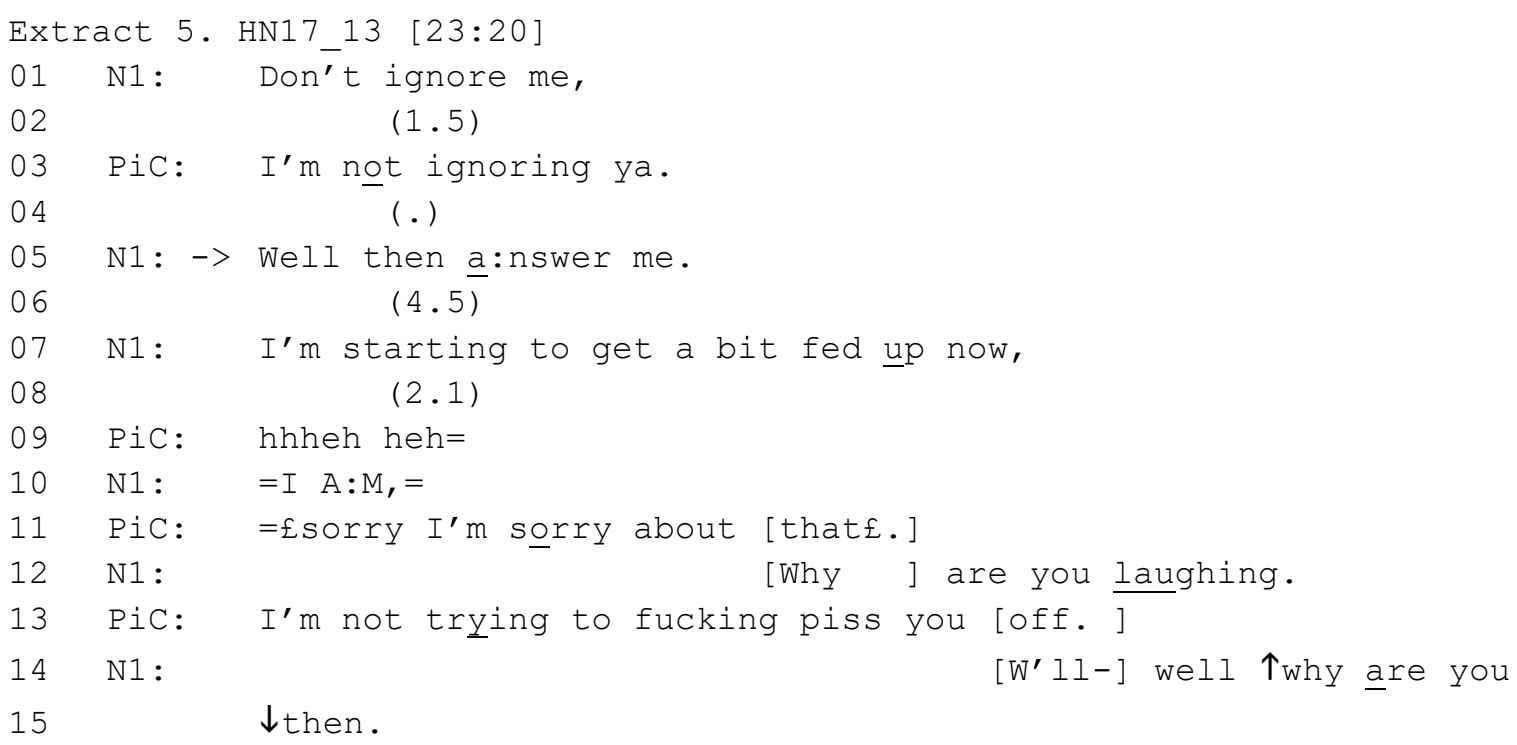

With his response to the N's complaint, the PiC shows that he can hear and understand $\mathrm{N}$ and that he can speak. With a well-prefaced directive, 'well then answer me' (line 05), the N highlights the inconsistency of the PiC claiming that he is not ignoring her (line 03), when he has indeed ignored her by not engaging with her summons prior to line 01 . Thus, like in Extract 4, the N presents a reasoned consequence of PiC's own words: formatted as the thenpart of an if-then construction, line 05 implies the $\mathrm{PiC}$ as already having provided the if- 
condition (if you are not ignoring me...). Moreover, the N's turn works to solicit the PiC's attention in another manner by pursuing the N's prior summons and designing her turn to make some type of acknowledgment relevant next. The $\mathrm{N}$ remains silent (line 06), treating this next slot as the PiC's turn space, and allows for the silence to continue past the maximal allowance for silence in a conversation (Jefferson 1988; Kendrick \& Torreira 2015). After the long silence, the $\mathrm{N}$ leverages the PiC's continued non-responsiveness by making a my-side complaint that uses an idiomatic expression, 'I'm starting to get a bit fed up now' (line 07). The N mitigates her complaint through terms such as 'starting' and 'bit,' thereby designing this complaint as a warning, from which he may infer what could happen next (e.g., she might walk away). Following 2.1 seconds of silence following this threat, the PiC responds with laughter (line 09). In the immediate next turn, the $\mathrm{N}$ reasserts her threat through confirmation, 'I A:M,' (line 10), to which the PiC immediately responds with an apology, '=£sorry I'm sorry about that£.' (line 11), which at least claims responsibility of having committed an offence (Goffman 1971; Robinson 2004). As indicated in the transcript, the N now has the PiC's attention, and she solicits an account for why the PiC is laughing and not taking her seriously (lines 12-15). While the conversation at this point is not centred on whether or not the $\mathrm{PiC}$ is coming down from the roof, the $\mathrm{N}$ immediate goal of making a connection with the $\mathrm{PiC}$ is achieved; the $\mathrm{PiC}$ comes down from the roof eight minutes later.

Extract 6 is a case in which the negotiator proposes and leverages upon a reasoned consequence of the PiC's account, without directly challenging the PiC's terms (as was the case in Extracts 4 and 5). In this instance a 911 emergency dispatcher (DIS) is speaking with a man who is threatening suicide by jumping off a bridge. Up to this point the caller revealed two important aspects about himself: that he left a hospital where he was admitted for mental illness, and that his girlfriend is pregnant with his baby. The dispatcher has talked to the PiC for about a minute. While the dispatcher learns that the $\mathrm{PiC}$ is sitting on the edge of a bridge, the $\mathrm{PiC}$ refuses to give his exact address for fear of the police coming to arrest him.

We are interested in how the dispatcher uses the caller's account for wanting to jump off the bridge as a basis for showing the $\mathrm{PiC}$ how this decision is incompatible with becoming a father. Our target in this instance is lines 06-07:

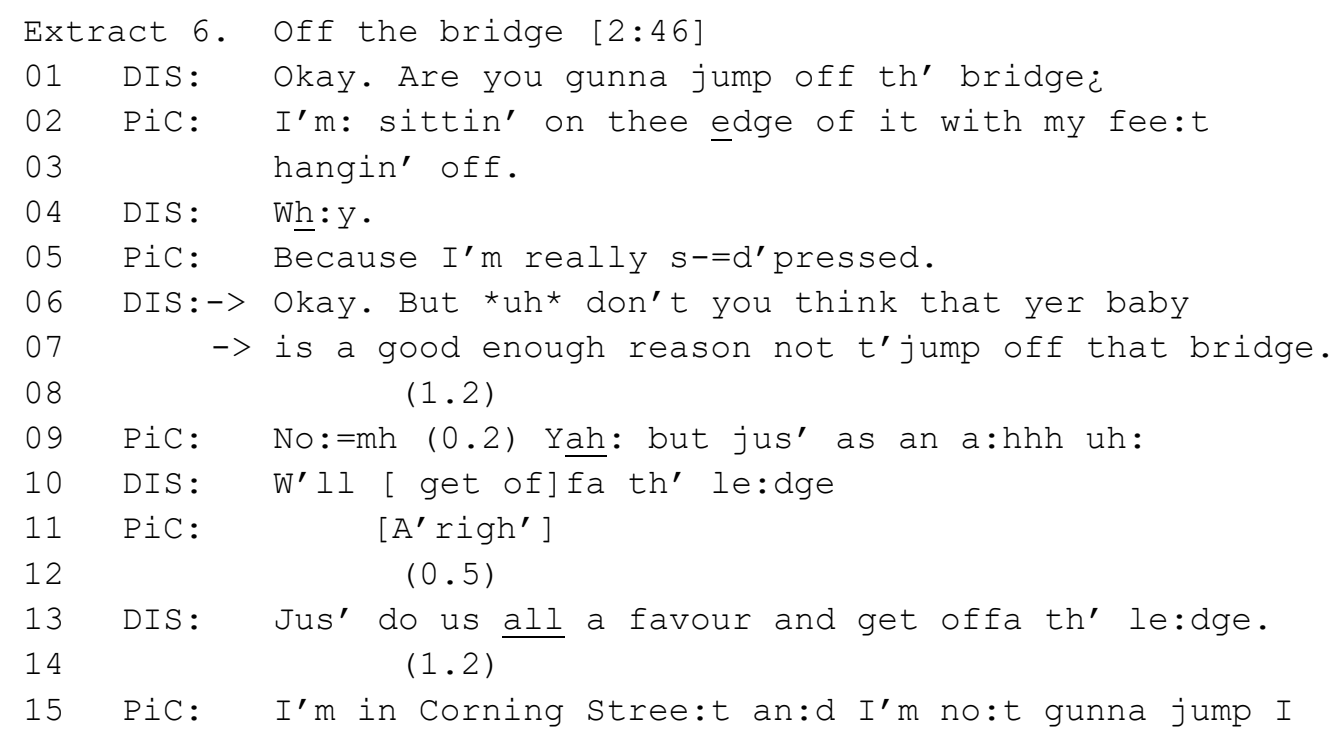


The dispatcher offers the caller an opportunity to expand on his account for wanting to jump off the bridge when, after getting a non-type conforming response (Raymond 2003) to her yes/no question (line 01), she works to solicit more from the PiC by asking 'Wh:y.' (line 04). Although the dispatcher gives him an opportunity to expand, the $\mathrm{PiC}$ provides a minimal response with one TCU that accounts for his decision, 'Because I'm really s- d'pressed' (line 05). The dispatcher registers his response with, 'Okay.' (line 06), but as a minimal response to her inquiry, does not accept his turn as relevant and complete (Heritage 1984). The dispatcher then builds her next turn as a contrast to the PiC's account with a turn initial, 'but *uh*', and draws from a resource the $\mathrm{PiC}$ already provided about his girlfriend being pregnant with his child (not shown). The dispatcher continues with, 'don't you think that yer baby is a good enough reason not t'jump off that bridge' (lines 06-07). With this turn, the dispatcher highlights a competing reason for not jumping off the bridge; that is, the responsibilities that accompany having a baby. The reasoned consequence here is about compatibility between the PiC's choice (ending life) and choices a presumably rational person who is about to become a parent would make (Sacks 1992).

The dispatcher designs her turn as a polar interrogative, where grammatically the 'don't you think $X^{\prime}$ prefers a yes-type response, while also implying shared knowledge and agreement (Heritage 2002). Through this turn design, the dispatcher undermines the PiC's reasoning to jump off the bridge because of depression, and designs a turn set up for strong agreement with the rational notion that one who is about to become a father should not commit suicide. The negotiator does so without directly challenging the PiC's experience of depression. We see the positive shift in the PiC's next turn where he initially produces 'No:' (line 09), which speaks to the larger course of action, before correcting with an agreeing, 'Yah' (line 09). The PiC continues his turn with a counter, 'but' (line 09); however, he trails off and does not complete his turn. The dispatcher seizes this opportunity to pursue her goal of getting him to a safe place when she issues a directive, 'W'll get offa th' ledge.' (line 10). Similar to Extracts 4 and 5, in response to a possible rejection, the dispatcher uses a wellprefaced turn to direct the $\mathrm{PiC}$ to the course of action she proposes (e.g., getting off the ledge). Moreover, in this case the PiC shifts from threatening suicide to making a promise not to jump (lines 15-16).

\section{FAILURES TO LEVERAGE UPON REASONING}

The above analysis demonstrates how negotiators and dispatchers can pose productive challenges to a person in crisis, whereby the challenge is grounded on a reasoning that the $\mathrm{PiC}$ cannot refute. We can better understand how this is achieved by looking at cases where the $\mathrm{N}$ fails to challenge and leverage upon reasoning; consequently, the N's proposal is easy for the $\mathrm{PiC}$ to refute.

Extract 7 starts when the negotiators arrived at the scene. The PiC is located on a rooftop and the Ns are on the ground below. In this case, $\mathrm{N}$ attempts to reason with the $\mathrm{PiC}$ by presenting him as a person that is completely in control of the situation (lines $01,03,05$ ). 


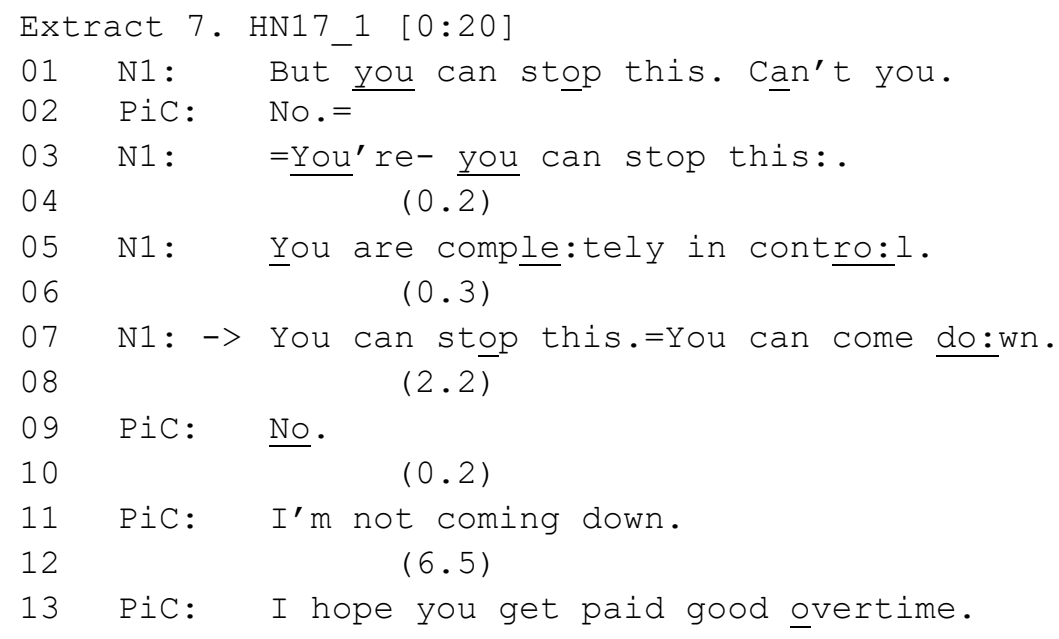

One tacit feature of crisis negotiation seems to be that while the known goal is to get the PiC to 'come down,' the PiC resists agreeing with the $\mathrm{N}$ to do so, and negotiators help the PiC through a process to make their own independent decision to 'come down'. Hence, the $\mathrm{N}$ proposes that the PiC is 'comple:tely in contro:1.' (line 05) and 'can stop this.' (lines 03 and 07). However, unlike the (interactionally) irrefutable reasoning we saw in the first section of analysis, here 'you can come do:wn' (line 07) is not built out of a logical reasoning that preserves the PiC's autonomy: $\mathrm{N}$ has not yet set up the local context that would warrant coming down as the irrefutable reasoned consequence of the PiC's own words. Extract 7 is taken from the early stages of a negotiation, at which point there is arguably little for the $\mathrm{N}$ to challenge and use as leverage. Indeed, challenges similar to those in Extracts 4-6 might not be appropriate yet for the same reason. But instead of building other actions to which the $\mathrm{PiC}$ might align at this stage, the $\mathrm{N}$ opens a slot that it is easy for the $\mathrm{PiC}$ to refute.

In comparison, Extract 8 is, like Extracts 4-6, taken from a later stage of the negotiation (sequentially similar to Extract 4), but unlike the earlier examples it shows how the $\mathrm{N}$ initially produces a productive challenge but fails to leverage it. This comes an hour into a different negotiation, where the PiC is barricaded in her flat, standing on a chair with a noose around her neck. The negotiators are in the corridor outside PiC's flat, and the $\mathrm{N}$ can see her through locked grill doors. We are focussing on what happens after the PiC agrees that her suicide does not have to happen yet (lines 07-09).

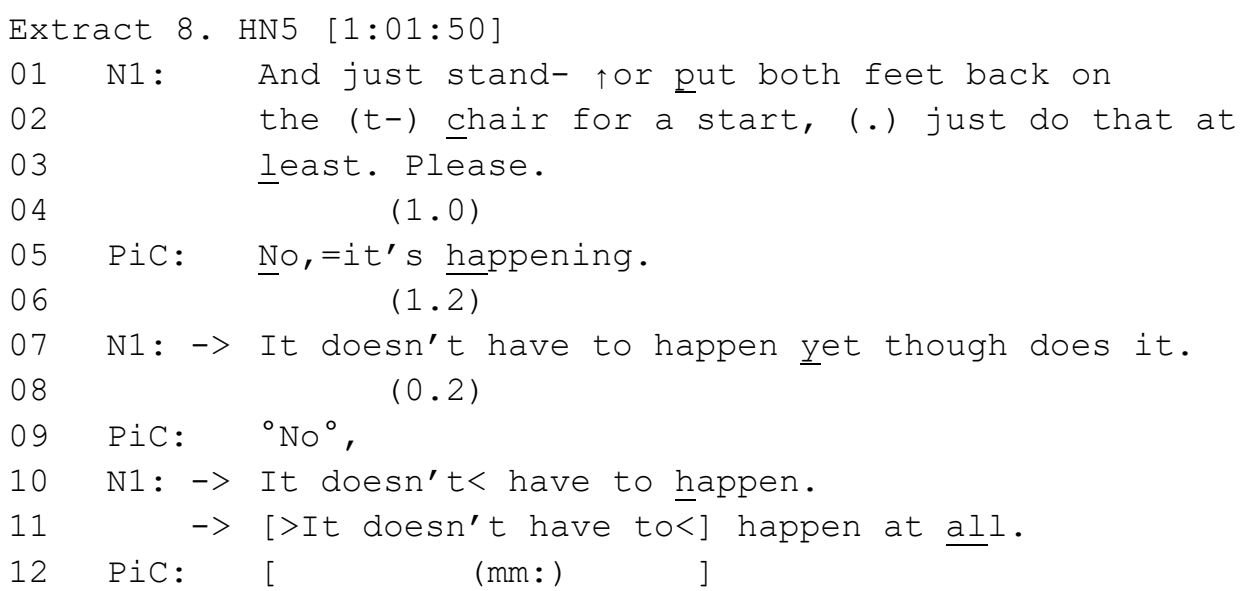


The N's proposal that 'It doesn't have to happen yet though does it.' (line 07), like the target turns in Extracts 4-6, acts like a challenge, highlighting a flaw in the PiC's account that 'it's happening' (line 05). In this way, the $\mathrm{N}$ does not challenge the PiC's choice to commit suicide, but challenges its imminence. At line 09 the PiC agrees with the N's proposal: the 'o $\mathrm{No}^{\circ}$,' is produced quietly following a $0.2 \mathrm{sec}$ gap, and might thereby project a reservation towards a stronger form of agreement. At the same time, this is an opportunity to productively leverage upon the challenge successfully posed in line 07 . However, the $\mathrm{N}$ misses the opportunity to do so, and the PiC's next response (line 13) is a strong rejection of PiC's next move (lines 10-11). In his next turn, the $\mathrm{N}$ first redoes what the PiC already agreed to, 'It doesn't have to happen.' (line 10). Then, in the same turn, he redoes what he did before by upgrading with an extreme case formulation (Edwards 2000), 'at all' at the end: 'It doesn't have to happen at all.' (line 11). By redoing what he already did (and what the PiC already agreed to), but in absolute terms (not doing it at all), the $\mathrm{N}$ opens opportunities for rejection and an escalation of the crisis, which is what happens in line 13 when the PiC responds, 'yeah it does,' (line 13). Following this extract the PiC starts kicking the chair she is on and thereby increases the risk of her falling off it; after extended and escalated threats of suicide the PiC eventually gives the Ns the keys to her door and they get her safely down. What we observe here is how a reasoned consequence can change from irrefutable to refutable with one turn of talk, which may have long term consequences for the negotiation.

\section{DISCUSSION}

This paper has shown how police negotiators and emergency dispatchers overcome resistance by building productive challenges that are effective in creating a turning point in the negotiation. By analysing live interactional data, we have identified the ways that negotiators and dispatchers highlight and leverage upon a reasoned consequence of the PiC's own account. This is a central part of our findings, and of our overall argument: that challenges can be productively built when they are based on the reality, terms and reasoning put forward by the PiCs themselves. Our analysis shows that these challenges support a positive rather than a negative turning point in the PiC's behaviour, by producing a demonstrable shift in the suicidal person's stance towards the negotiation. The negative examples (Extracts 7 and 8) confirmed this finding by showing how less logically and interactionally founded arguments were treated as refutable by the $\mathrm{PiC}$, which is not only refuted but may also lead to a negative turning point (Extract 8). In this discussion, we unpack further our notion of 'irrefutable reasoning' and address some of the wider implications of our findings.

Firstly, the shifts observed are all significant in terms of the professional's (negotiator or dispatcher) goals to ensure the $\mathrm{PiC}$ is safe. The positive cases included a PiC's removal of the noose around their neck (Extract 4), a promise not to jump off the bridge (Extract 6), and substantive engagement following extended disengagement (Extract 5). These are all small, yet major achievements in dealing with the strong resistance typically observed of a person in crisis. Secondly, the finding that challenges may be used productively, in the forms of 
questions ('don't you think X', Extract 6; 'it doesn't have to happen yet though does it', Extract 8), and well-prefaced if-then imperatives ('well if it doesn't make a difference... take it off then', Extract 4; 'well then answer me', Extract 5), runs counter to the recommendations made in much of the crisis negotiation literature, that professionals ought to avoid challenging the person in crisis (e.g., James, 2007; Vecchi et al. 2005). Our interpretation of this disparity is that the resources identified in this paper represent the tacit expertise that negotiators possess, which, until now, have not been uncovered and detailed in studies of unfolding real-time negotiations (see Rubin 2016). Our conclusion is not that negotiators should challenge a person in crisis whenever and however they can; rather, our findings specify how a challenge can be done productively building on logic and reasoning presented by the person in crisis themselves. Some challenging questions and imperatives can be productive for the crisis encounter, precisely because they occur, and leverage upon, emerging sequences of talk.

This brings us to another key aspect of our findings, namely that the PiCs demonstrate an apparent unwillingness to present themselves as unreasonable or irrational. Thus, a refusal to accept the negotiator-initiated challenges presented here, would constitute a failure in choosing logic, which would thereby undermine the PiC's ability to act according to mundane reasoning and rationality (Pollner 1974). For example, following the dispatcher challenging the PiC's threat to jump as incompatible with being a father to a baby (Extract 6), the PiC demonstrably struggles to reject this confrontation, and soon after displays a significant shift in promising to the dispatcher not to jump. While a response is akin to 'I don't care' seems conceivable here, it does not happen, and neither does it do so elsewhere in the data, indicating that the PiC, given an opportunity to do so in the interaction, show they are rational beings. In this way, our findings mirror some of Sacks's (1992) observations, and in line with his project, we have shown how such opportunities arise based on the professional party leveraging the PiC's own talk.

In a wider perspective, our study contributes towards identifying what constitutes interactional competence in different professional contexts (see e.g. Rine and Hall 2011 on teaching). Our findings have implications for how negotiators go about doing their job, as we still know relatively little about what is effective in real, rather than simulated, crisis events. Evaluations of the efficiency and value of training (e.g., Hasselt et al. 2006) assess roleplayed and simulated events, not real negotiations. While simulation has some value, other research has shown striking and consequential differences between role-played encounters and the real encounters they are meant to mimic (Atkins et al. 2016; Stokoe 2013). Indeed, almost twenty years ago, Taylor and Donald (2004) showed that this distinction is true for simulated and actual crisis negotiations. We argue that based on these, and our own findings, it is necessary to further examine what happens in real encounters, and crucially to do these alongside simulations, where the stakes are different from real negotiations. However, our aim was less to challenge existing guidance and models, but to show what works as part of the collective endeavour to best support persons in crisis.

Specifically, our findings contribute toward an understanding of the necessarily stepwise, turn-by-turn mechanisms through which successful negotiation occurs. Although negotiators rarely get explicit agreement from the person in crisis, they still have resources available to ensure that the person's remains in relative safety. These resources may explicate 
some of the general, outcome-oriented approaches to crisis negotiation, for example, the 'influence' and 'behavioural change' stages in the Behavioural Influence Stairway Model (Vecchi et al. 2005). One argument in favour of such a connection is our observation that 'irrefutable reasoning', similar to influence and behavioural change, only tends to occur later on in the encounter. Also in Extracts 2 and 3, the negotiation had been going on for an extended time before the significant shifts in the PiC's stance occurred. While our notion of early and late remains unspecified, for a challenge to be productive it necessitates an interactional past; that is, something to leverage connections and logic upon (this was not the case in Extract 7). Moreover, the negotiators' claim to be 'fed up' in Extract 5 is quite naturally only found several hours into the negotiation. The evidence for this is partly in the strong $\mathrm{PiC}$ stance found early in the encounter, and that all instances of 'irrefutable reasoning' we have found occur at least a couple of minutes into 911 calls, and 30 minutes into the crisis negotiations. However, we do find refuted reasoning later on in these encounters, which illustrates the ongoing struggle of the negotiation (see Extract 8).

More generally, we found that turns which open up slots for agentive, rational, proactive displays of decision-making on the part of the person in crisis are most effective. This is part of how, and when, the 'irrefutable reasoning' works. We identified independence and agency in the actions formed by the persons in crisis, and a key feature of what makes these challenges productive is that they do not challenge the basis for the PiC's independence, but rather treats this independence as a given. The 'irrefutable reasoning' is characterised by not challenging PiC's rights and autonomy to end life, and demonstrably, such moves work to open slots for $\mathrm{PiC}$ to display and demonstrate agency, while not threatening the commitment and legitimacy of the course of their action. Furthermore, our findings show that, while just about anything can be resisted or rejected in interaction, some actions are easier to resist than others. Unpacking the role of language, turn design, and the interactional sequence is key to identifying and understanding what these actions look like, and in what circumstances they might be productive for the negotiation.

There are wide-ranging benefits of proceeding to rigorously unpack the role of language in crisis negotiations in future research. In this paper we address comparable phenomena identified in data from UK and US contexts. Previously, Giebels and Taylor (2009) addressed the relevance of cultural difference in how arguments are responded to in crisis negotiations, a point which also Grubb (2010) highlighted as core to future research on crisis negotiations. We would like to add that such comparative future research should be constituted on bottom-up analyses of how, for example, agency and control are made relevant in and through the crisis encounter.

Finally, our findings may help specifying some of the concepts used in the crisis negotiation literature, for example the 'active listening skills' as incorporated in the Behavioural Influence Stairway Model. But whether or not the Behavioural Influence Stairway Model, or other frameworks used in crisis negotiation training, are relevant to use, we have argued that a priori factors and variables are less useful to negotiators than understanding what actually works, in terms of words to say and turns to take. We maintain this view: it is not just that words matter; words matter with reference to past, present and future turns of talk, which in crisis negotiations can help managing interactional sequences productively, towards positive outcomes. 


\section{REFERENCES}

Atkins, S., Roberts, C., Hawthorne, K., \& Greenhalgh, T. (2016). 'Simulated consultations: a sociolinguistic perspective', BMC Medical Education, 16/1: 16.

Atkinson, J. (1978). Discovering suicide: Studies in the social organization of sudden death. University of Pittsburgh Press.

Atkinson, J. M., \& Heritage, J. (1984). Structures of social action. Cambridge University Press.

Charlés, L. L. (2007). 'Disarming People with Words: Strategies of Interactional Communication that Crisis (Hostage) Negotiators Share with Systemic Clinicians', Journal of Marital and Family Therapy, 33/1: 51-68.

Edwards, D. (2000). 'Extreme case formulations: Softeners, investment, and doing nonliteral', Research on language and social interaction, 33/4: 347-73.

Fox, B. A., Thompson, S. A., Ford, C. E., \& Couper-Kuhlen, E. (2013). 'Conversation analysis and linguistics'. Sidnell J. \& Stivers T. (eds) The handbook of conversation analysis, pp. 726-40. John Wiley \& Sons.

Garcia, A. (2017). 'What Went Right: Interactional Strategies for Managing Crisis Negotiations during an Emergency Service Call', The Sociological Quarterly, 58/3: 495518.

Giebels, E., \& Taylor, P. J. (2009). Interaction patterns in crisis negotiations: Persuasive arguments and cultural differences. Journal of Applied Psychology, 94/1: 5.

Goffman, E. (1971). 'Remedial interchanges', Relations in public: Microstudies of the public order, $95-187$.

Grubb, A. (2010). Modern day hostage (crisis) negotiation: The evolution of an art form within the policing arena. Aggression and Violent Behavior, 15/5: 341-348.

Haselow, A. (2011). 'Discourse marker and modal particle: The functions of utterance-final then in spoken English', Journal of Pragmatics, 43/14: 3603-23.

Hasselt, V. B. Van, Baker, M. T., Romano, S. J., Schlessinger, K. M., Zucker, M., Dragone, R., \& Perera, A. L. (2006). 'Crisis (Hostage) Negotiation Training', Criminal Justice and Behavior, 33/1: 56-69.

Heritage, J. (1984). 'A change-of-state token and aspects of its sequential placement. Structures of social action: Studies in conversation analysis, ed. by J. Maxwell Atkinson and John Heritage, 299-345',

- (2002). 'The limits of questioning: Negative interrogatives and hostile question content', Journal of Pragmatics, 34/10-11: 1427-46.

- (2015). 'Well-prefaced turns in English conversation: A conversation analytic perspective', Journal of Pragmatics, 88: 88-104.

Houwen, F. Van der, \& Sliedrecht, K. (2016). 'The form and function of formulations: Coconstructing narratives in institutional settings', Journal of Pragmatics, 105: 55-8.

Husky, M., Swendsen, J., \& Ionita, A. (2017). 'Predictors of daily life suicidal ideation in adults recently discharged after a serious suicide attempt: a pilot study', Psychiatry research, 256: 79-84.

James, R. K. (2007). Crisis intervention strategies., 6th ed. Thomson Brooks/Cole.

Jefferson, G. (1988). "Notes on a possible metric which provides for a "standard maximum" silence of approximately one second in conversation'. Roger D. \& Bull P. (eds) Conversation: An interdisciplinary perspective. Clevedon, UK: Multilingual Matters.

Kendrick, K. H., \& Torreira, F. (2015). 'The Timing and Construction of Preference: A Quantitative Study', Discourse Processes, 52/4: 255-89. 
Kleiman, E. M., \& Nock, M. K. (2018). 'Real-time assessment of suicidal thoughts and behaviors', Current Opinion in Psychology, 22: 33-7.

Klonsky, E. D., \& May, A. M. (2014). 'Differentiating Suicide Attempters from Suicide Ideators: A Critical Frontier for Suicidology Research', Suicide and Life-Threatening Behavior, 44/1: 1-5. DOI: 10.1111/sltb.12068

Knowles, G. J. (2016). 'Social psychological dynamics of hostage negotiation: forensic psychology, suicide intervention, police intelligence/counterintelligence, and tactical entry', Journal of Criminal Psychology, 6/1: 16-27.

Lakeman, R., \& Fitzgerald, M. (2009). 'Ethical suicide research: A survey of researchers', International Journal of Mental Health Nursing, 18/1: 10-7.

McMains, M., \& Mullins, W. (2014). Crisis negotiations: Managing critical incidents and hostage situations in law enforcement and corrections. Routledge.

Miles, E. W. (2013). 'Developing Strategies for Asking Questions in Negotiation', Negotiation Journal, 29/4: 383-412.

'Office for National Statistics'. (2017). Suicides in Great Britain: 2016 registrations. Retrieved May 18, 2018, from $<$ https://www.ons.gov.uk/peoplepopulationandcommunity/birthsdeathsandmarriages/dea ths/bulletins/suicidesintheunitedkingdom/2016registration>

Pollner, M. (1974). 'Mundane Reasoning', Philosophy of the Social Sciences, 4/1: 35-54.

Raymond, G. (2003). 'Grammar and social organization: Yes/no interrogatives and the structure of responding', American sociological review, 68/6: 939-67.

Rine, E. F., \& Hall, J. K. (2011). Becoming the teacher: Changing participant frameworks in international teaching assistant discourse. Hall J. K., Hellermann J \& Pekarek Doehler S. (eds) L2 interactional competence and development (pp. 244-271). Bristol: Multilingual Matters.

Robinson, J. D. (2004). 'The Sequential Organization of \&quot;Explicit\&quot; Apologies in Naturally Occurring English', Research on Language \& Social Interaction, 37/3: 291330. Lawrence Erlbaum Associates, Inc.

Rogan, R. G. (2011). Linguistic style matching in crisis negotiations: A comparative analysis of suicidal and surrender outcomes. Journal of police crisis negotiations, 11/1: 20-39.

Roulston, K. (2010). 'Interview "problems" as topics for analysis', Applied Linguistics, 32/1: $77-94$.

Royce, T. (2005). 'The Negotiator and the Bomber: Analyzing the Critical Role of Active Listening in Crisis Negotiations', Negotiation Journal, 21/1: 5-27.

Rubin, G. (2016). Negotiation Power Through Tag Questions in Crisis Negotiations. Georgetown University. Retrieved April 12, 2018, from $<$ http://search.proquest.com/openview/d5e3991f681d1040314ab2fe82736d3b/1?pqorigsite $=$ gscholar $\& \mathrm{cbl}=18750 \&$ diss $=\mathrm{y}>$

Sacks, H. (1966). No one to turn to. University of California, Berkeley.

- (1992). Lectures on conversation (Vols. 1 and 2). (G. Jefferson, Ed.). Oxford: Blackwell.

Schegloff, E. A. (2007). Sequence organization in interaction. Cambridge: Cambridge University Press.

Stokoe, E., \& Sikveland, R. (2017). 'The Conversation Analytic Role-play Method'. Pink S., Fors V., \& O'Dell T. (eds) Theoretical Scholarship and Applied Practice, pp. 73-96.

Stokoe, E. (2013). 'The (in) authenticity of simulated talk: comparing role-played and actual interaction and the implications for communication training', Research on Language \& Social Interaction, 46/2: 165-85.

Taylor, P. J., \& Donald, I. (2004). 'The Structure of Communication Behavior in Simulated and Actual Crisis Negotiations', Human Communication Research, 30/4: 443-78. 
Taylor, P. J., \& Thomas, S. (2008). 'Linguistic Style Matching and Negotiation Outcome', Negotiation and Conflict Management Research, 1/3: 263-81.

Tracy, S. J. (2002). 'When questioning turns to face threat: An interactional sensitivity in 911 call-taking', Western Journal of Communication, 66/2: 129-57.

Vecchi, G. M., Hasselt, V. B. Van, \& Romano, S. J. (2005). 'Crisis (hostage) negotiation: Current strategies and issues in high-risk conflict resolution', Aggression and Violent Behavior, 10/5: 533-51.

Voss, C., \& Raz, T. (2016). Never Split the Difference: Negotiating as If Your Life Depended on it. Random House. 